\title{
COMMENTARY
}

\section{Living with Cancer: Through the Eyes of the Patient and the Physician}

José Manuel Vigo · Paula Jiménez Fonseca • Caterina Calderon ·

Alberto Carmona-Bayonas · Enrique Grande

Received: May 23, 2016 / Published online: July 1, 2016

(C) The Author(s) 2016. This article is published with open access at Springerlink.com

\section{ABSTRACT}

This article is co-authored by a patient with colon cancer and his treating oncologist, who interact at two different levels: the instrumental and the emotional and affective one. The patient relates in detail his personal experiences struggling with cancer, including his fears, expectations, purposes, and attitudes through the most important events in the evolution of his illness. The professional

Enhanced content To view enhanced content for this article go to http://www.medengine.com/Redeem/ OFD4F0604BB592CA.

J. M. Vigo

Oviedo, Spain

P. J. Fonseca $(\square)$

Hospital Universitario Central de Asturias, Oviedo, Spain

e-mail: palucaji@hotmail.com

C. Calderon

Department of Personality, Assessment and Psychological Treatment, Faculty of Psychology, University of Barcelona, Barcelona, Spain

A. Carmona-Bayonas

Hospital Universitario Morales Meseguer, Murcia, Spain

E. Grande

Hospital Universitario Ramón y Cajal, Madrid, Spain reflects how patient-based communication and shared decision-making impact on quality of life and coping with cancer.

Keywords: Cancer; Coping; Patient experience; Quality of life; Shared decision-making

\section{THE PATIENT'S EXPERIENCE}

In the following lines, I will attempt to show how I feel and what my expectations and needs are as a patient living with incurable cancer.

I am a 57-year-old man, a businessman, social drinker, and I smoke one pack of cigarettes per day with long periods of not smoking. I cannot recall having had any kind of illness during my life except for the odd flu.

My first symptoms appeared when, during my daily commute to work, I had to stop the car for some minutes, because of pain in my legs that was all but unbearable. At first I thought it might be an episode of temporary lumbago, so I decided not to go to the doctor. During the following weeks, other symptoms appeared along with the previous ones: I had to get up two or three time a night to urinate small 
amounts and later I had constipation and bloody mucous in my feces. With these symptoms, I started to read and consult different sources on the Internet and concluded that I had a serious illness-in fact, I was sure that I had colon cancer.

I consulted a private physician and told him about my symptoms and suspicions. A colonoscopy was performed that detected a tumor that filled $70 \%$ of the lumen of the colon. The subsequent biopsy confirmed that it was adenocarcinoma of the colon.

While it may seem strange, the diagnosis did not discourage me; just the opposite. I was so convinced that my concerns were now focused on finding solutions. I think that with a disease like this one, you derive your serenity and high spirits from information. I believe that the patient who is knowledgeable about their illness can help their doctor in the treatment process by maintaining a sensible dialogue with them. Knowing what causes the symptoms, no matter how serious the disease is, provides a certain peace of mind and strength to fight. For sure, during the first days, I wondered why this had happened to me and I was invaded by fear.

Once all the tests were complete, the scanner confirmed the presence of liver lesions and possible peritoneal tumor implants.

Before a full month had gone by and with the studies completed in the hospital in the city where I live, I was thrilled to be given the date for my colon surgery. Being familiar with the hospital, its grandiose modern architecture, the computer systems, how the doctors treated me, and all the details I had observed had instilled in me a sense of total trust.

After the operation, I was happy and tremendously grateful to the surgeon who even told me about the difficulties that had arisen during the surgery, which had taken several hours longer than usual. The pathology report stated that there were no signs of malignancy in the margins of the specimen and that all the lymph notes that had been removed were tumor-free, so I thought that the first battle had truly been won.

In spite of everything, the presence of lesions in the liver and peritoneum continued to concern me, considering that I might need chemotherapy. The situation made me so anxious that I could not wait to see the oncologist. At that time, I intended to pursue possible solutions to a situation with a poor prognosis.

I finally met the oncologist! My partner went with me to my appointment with the oncologist, a great professional, head of a department, and research project leader. He explained to us that I have systemic disease and that the only possible solution was chemotherapy. He convinced us to participate in a clinical trial. We asked him about the life expectancy for someone in our situation, and he answered that if left untreated, less than 1 year and with chemotherapy and the present spread of the disease, I could easily last longer than that. At that first visit, he did not seem terribly approachable, which made it hard to ask questions. We signed the consent form for the trial and he gave us an appointment to start chemotherapy. What I had heard did not worry me. I intended to leave the doctor's office and begin to check out how true all the information was using all the means within my reach. Again, understanding new data and reading the information about the study very carefully kept me from becoming discouraged and frustrated, as the doctor's words might have otherwise done. We went to the following appointment with new knowledge and a treatment plan that could improve my disease. I had even consulted a surgeon because I did not want to close any doors on a curative treatment, liver and peritoneal surgery, even 
though I knew that I had few options. I had also received information about a healthy lifestyle, diet, and exercises to round out my fight against cancer. The anticipation of being cured excited me once again. All I needed was for the chemotherapy to reduce the tumor mass. Every time I went for chemotherapy or felt exhausted or disabled by the cramping in my hands and feet, I reminded myself that this treatment was my choice and that gave me strength for the fight.

After 3 months of treatment, the scanner report confirmed an excellent response to treatment with the liver metastases shrinking by more than $50 \%$ and the peritoneal ones by more than $80 \%$.

Almost 6 months after the initial diagnosis, I underwent surgery for the liver metastases and later for the peritoneal implants.

Much sooner than expected, I relapsed. It had not even been 2 months and the scanner detected new implants in my peritoneum. I was in a tricky situation and, what is more, the oncologist we had seen previously was not available, so an oncologist from the department assessed us. When we spoke with her, we were very fearful; however, we found ourselves dealing with a warm person who knew how to respond to and understand our doubts. Without sidestepping the dismal truth, she offered us a chemotherapy regimen, sharing the treatment choice with us. She encouraged us to set goals and fight to reach them.

Over the following 6 months, I underwent two imaging studies that revealed that the tumor was under control. I have later continued with a maintenance treatment plan that allows me to go to work for a few hours every day and to live with my family almost normally. The doctor brings me up to date regularly about the progress being made in treatments and has pointed us to interesting websites of oncological societies or patient associations. I have recently agreed to participate in a study on lifestyle and diet that is being coordinated by the head nurse at the day hospital. Likewise, I try to help other patients and support them, just as my family supported me.

It has been 2 years since my diagnosis and I do not know how much longer I will live. What I do know is that so far, my fight has been worthwhile. Although I have had to give up a lot of things along the way, the most important things-my family, my friends, and my workhave stayed with me and have helped me in everything much more and much better than I could have ever dreamt. Other people with whom I have crossed paths since the diagnosis, my oncologist, the nursing staff at the day hospital, and countless other professionals, have been key and they have given me great confidence, knowing that I put my life in their hands with every new treatment or medical decision.

\section{PHYSICIAN'S PERSPECTIVE}

Cancer is a major health problem worldwide and carries a huge impact for the patient. The diagnosis is typically unexpected, causing psychological distress in virtually all patients, including uncertainty, disbelief, despair, vulnerability, fear, anxiety, and the need to confront work, economic, family, and psychosocial consequences. Furthermore, in recent decades, improved diagnostic techniques and the availability of multiple treatments, including various chemotherapy schemes and molecular-targeted drugs, can lower mortality and improve prognosis.

All of this involves complicated decision-making, a process during which, as oncologists, we must interact with the patients 
on a high emotional level; take them into account when deciding on the treatment plan, and integrating their perspectives, concerns, and preferences. Moreover, patients interact with their physicians in very different ways and become involved in the process in different ways as well, depending on factors that have to do with the doctor's communication style, their coping style, and other motivations.

Patient-based decision-making models seek not only to increase satisfaction but also to improve their coping, quality of life, and the clinical course of disease. This patient is an educated businessman with a proactive attitude, looking for information and alternatives. It was therefore imperative to help him understand; to resolve all the doubts that arose for him along the way, and provide him with the best sources to consult, something that, nowadays, should include scientific and patient association websites, as the patient mentioned.

Because of the diagnosis of advanced, unresectable, and disseminated cancer, surgery alone would not suffice to cure the cancer; hence, the rush to consult with oncology.

An important part of the initial communication centers on explanations about the tumor, prognosis, need for chemotherapy, treatment plan, and managing toxicity. Typically, the chemotherapy options available are discussed, taking into account the benefits and possible disadvantages. This then becomes the foundation on which to make consensual, individualized decisions. Whenever available, clinical trials are the best option for patients who must receive clear information about the trial's aim and all the procedures involved.

As in most patients, having advanced, incurable cancer arouses enormous uncertainty and an initial feeling of loss of control that, if they persist, can have a direct, negative effect on coping with the illness. The uncertainty arises from the ominous perception of the future or from the doctor's failure to convey effective information about where they are at in the process, possibly as a result of communication barriers (conspiracy of silence, emotional blockage, the professional's skill, etc.).

It is important to be mindful of the fact that the physician and patient interact in two main spheres: the technical, scientific, or instrumental one, as well as the domain that focuses on the patient's emotional and affective aspects. Although an important part of the communication centers on the detailed exchange of practical information about the treatment, the patient is going to react strongly to this information on an emotional level and other social, family, or affective aspects are going to be put on the table. Instrumental communication is the foundation of medicine and, as such, should be positively valued by patients, instilling into them trust in their doctor. However, in oncology, the emotional and/or affective component is more important than in other fields, given the connotations of cancer. Though both the technical and emotional aspects are positively correlated, patients give greater weight to the latter. Oddly, this often means that patients do not assess their doctors on their technical abilities, but on their emotional competence to relate to them. Since patients prioritize emotional information, one approach associated with favorable results is the so-called patient-based communication model, with both an affective and a participative component. In practice, it involves the following attitudes: the professional needs to show an affective component (empathy, concern, reassuring tone of voice, etc.) and to take into account the patient's preferences, perspectives, and values, since they should be involved in 
deciding on the treatment plan, through unhurried explanations, the use of open-ended questions, etc.

In short, patient-based communication, in this case a patient with advanced, incurable cancer, and shared decision-making about the advisability of starting chemotherapy have a psychological impact and affect their quality of life, coping, and the course of the disease; hence, the patient's biopsychosocial environment must be understood, and empathy and openness to dialogue must be shown.

\section{ACKNOWLEDGMENTS}

The patient would like to thank the physician and the rest of the healthcare personnel at the Hospital Universitario Central de Asturias for their efforts. Technical assistance with translation of the manuscript for submission was provided by Priscilla Chase. The authors are fully responsible for all content and editorial decisions and received no financial support or other form of compensation for elaborating this manuscript. All named authors meet the International Committee of Medical Journal Editors' (ICMJE) criteria for authorship for this manuscript, take responsibility for the integrity of the work as a whole, and have given final approval for the version to be published. The opinions expressed in the manuscript are those of the authors. No funding was received for publication of this article.

Disclosures. José Manuel Vigo, Paula Jiménez Fonseca, Caterina Calderon, Alberto Carmona Bayonas, and Enrique Grande have nothing to disclose.

Compliance with Ethical Guidelines. This article does not contain any new studies with human or animal subjects conducted by any of the authors.

Peer Review. Please note, contrary to the journal's standard double-blind peer review process, as a commentary this article underwent review by a member of the journal's Editorial Board.

Open Access. This article is distributed under the terms of the Creative Commons Attribution-NonCommercial 4.0 International License (http://creativecommons.org/licenses/ by-nc/4.0/), which permits any noncommercial use, distribution, and reproduction in any medium, provided you give appropriate credit to the original author(s) and the source, provide a link to the Creative Commons license, and indicate if changes were made. 